\title{
Reservoir Classification and Evaluation Methods Based on R35 Pore Throat Radius
}

\author{
Yangfan Li, Hua Cai, Chao Cheng \\ CNOOC Ltd-Shanghai, China
}

\begin{abstract}
Reservoir Classification and Evaluation is an important section in the process of the research for reservoir development. Based on the analysis of core capillary pressure data, this research proposed: The relationship between R35 (Mercury enters the saturation of $35 \%$ corresponding to the pore throat radius) and permeability $(K)$, porosity $(\Phi)$; Establishment of classification and evaluation chart with the parameters such as $\mathrm{R} 35, K, \Phi$, for the LS gas field. By putting a large number of conventional core analyzing data of the physical properties on the chart, the quality of each gas formation in accordance with the core could be evaluated. For the same formation, the significant change of the parameters $(\mathrm{R} 35, K$, and $\Phi)$ could indicate that the reservoir has a severe heterogeneity. For example, after analyzing the main factors of diagenesis which affect reservoir heterogeneity through the thin slice identification, scanning electron microscopy and other laboratory data of E15 reservoir, the conclusion could be obtained: Dissolution is the most significant factor which influences the heterogeneity of the reservoir. The reservoir classification and evaluation Chart of R35 could help to evaluate the reservoir physical properties intuitively and efficiently.
\end{abstract}

Keywords-R35 Pore Throat Radius; porosity; permeability; compaction; cementation

\section{INTRODUCTION}

Integrating the reservoir parameters from microscopic pore structure characteristics of the reservoir is an important method for the research of reservoir classification and evaluation (Wang et al. 2002). Geologists have proposed many methods for Classification and Evaluation based on microscopic pore structure characteristics of the reservoir.

The methods are mainly divided into two categories: Division methods and Clustering methods. The Division methods were significantly influenced by subjective human factors, and the Clustering methods must be based on massive amounts of basic data analysis in order to obtain accurate and complete results (Tang et al. 2006).

LS gas field has a strong heterogeneity. A typical reservoir showed great differences on permeability in different cores due to the different pore structure. As a result, the Classification and Evaluation work under conventional porosity and permeability parameters could not obtain the satisfactory results.

The combination of R35 pore throat radius data, permeability and porosity which based on the mercury penetration, conventional physical property, scanning electron microscope, etc., was used to establish the chart for classification and evaluation as a new method in this study.

\section{THEORY}

\section{A. R35 Pore Throat Radius and Diffusivity Coefficient}

In the core capillary pressure test, pore throat radius in accordance with the mercury saturation in $35 \%$ is defined as R35 pore throat radius. The larger size of the R35 pore throat radius indicates the better physical property of the core.

Diffusivity Coefficient is a parameter for evaluation of the pressure propagation, the physical interpretation is the formation acreage of the pressure propagation in unit time, it could be calculated as follow:

$$
\eta=\frac{k}{\varphi \mu C_{t}}
$$

Where $K$ is the permeability, $\mathrm{mD} ; \Phi$ is the porosity, $\%$; $C_{t}$ is the total compressibility of the reservoir; $\mu$ is the viscosity of the fluid, $\mathrm{mPa} \cdot \mathrm{s}$.

In the same reservoir, the $\mu$ and $C_{t}$ have very small variations. It indicates that there is a specific relationship between $\mathrm{R} 35$ and the value of $K / \Phi$.

\section{B. Matching of the relationship between $R 35$ and $K / \Phi$}

Productivity simulation formula is related with the core experiments. The gas production under different pressure could be simulated by using the simulation of reservoir state which includes: Initial water saturation, Salinity of Formation Water, Overlying Pressure, Reservoir Pressure, Reservoir Temperature, etc.

H. D. Winland et al. (1980, 1992, and 2007) had matched the data from Spindle Oil Field, and proposed an experience equation as follow:

$$
R 35=5.395\left[\frac{K^{0.588}}{(100 \varphi)^{0.864}}\right]
$$

Aguilera R et al $(2002,2004)$ had matched the data from North America, and proposed another experience equation as follow:

$$
R 35=2.665\left[\frac{K}{(100 \varphi)}\right]^{0.45}
$$

Where the R35 is the pore throat radius in accordance with the mercury saturation in $35 \%$, um; $K$ is the permeability, $\mathrm{mD} ; \Phi$ is the porosity, $\%$. 
Eq.2 has one linear parameter and two exponential parameters. Eq.3 has one linear parameter and one exponential parameter.

\section{RESULTS}

\section{A. Equation in accordance with the LS gas field}

Combine the effective R35 and $K / \Phi$ values from the cores in 4 typical wells of LS gas field, there are 99 pair values. After matching the relationship between the R35 and $K / \Phi$ by using the Eq.3, the linear parameter and exponential parameter in accordance with this field follow the eq. 3 could be obtained.

The matching result is shown in Figure.1. As can be seen in the Figure, the relationship between the R35 and $K / \Phi$ has a high correlation coefficient, above $90 \%$. The R35 and $K / \Phi$ display a power function.

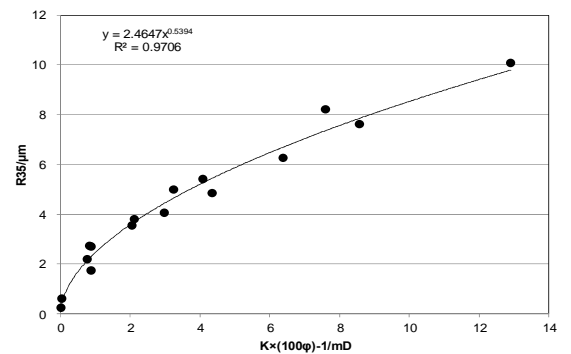

Figure 1. R35 vs $K / \Phi$ of the typical Wells

Combine the effective R35 and $K / \Phi$ values from the cores in all the wells of LS gas field, there are also 99 pair values. After matching the relationship between the R35 and $K / \Phi$ by using the Eq.3, the result is shown in Figure.2. As can be seen, the correlation coefficient is lower, less than $80 \%$.

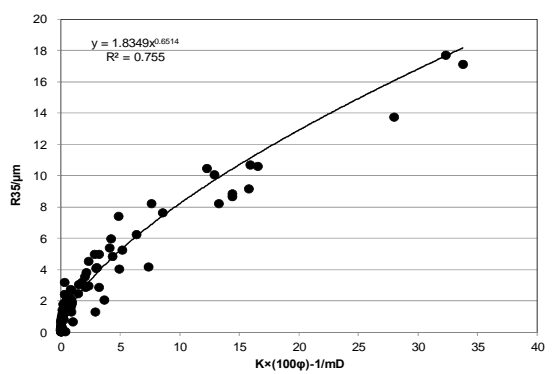

Figure 2. R35 vs $K / \Phi$ of the gas field

The decline of the correlation coefficient is mainly resulted by the cores from the reservoirs with low permeability and low porosity. The errors of the mercury intrusion test could not be avoided.

After the two matching work, the experience equation could be expressed as follow:

$$
R 35=1.8349\left[\frac{K}{(100 \varphi)}\right]^{0.6514}
$$

\section{B. Chart in accordance with the Equation}

The chart in accordance with the Eq. 4 could be drawn with the 977 pair data of porosity and permeability. The chart is shown in Figure.3. By using this figure, the ranges of R35, porosity, permeability of each reservoir in the gas field could be clearly searched, and the physical property could be evaluated in a short time.

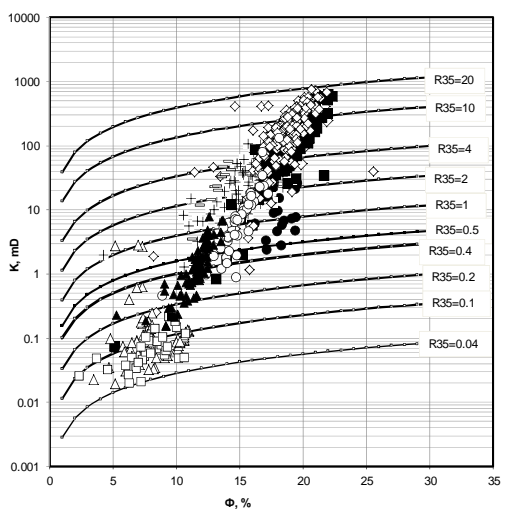

Figure 3. R35 evaluation chart

\section{Analysis of the reservoir heterogeneity}

- Main reason

The E15 with thickness around $85-120 \mathrm{~m}$, is a low permeability gas reservoir. It could be separated into four sub layers: E15a, E15b, E15c and E15d.

The Well 2, Well4 and Well 6 have cores in E15a. The Well 6 produces only E15a, and hasn't natural productivity. After Sand Fracturing Work, Well 6 could maintain production and has the AOF about $3.5 \times 10^{4} \mathrm{~m}^{3} / \mathrm{d}$. Well 2 produces four layers: E9, E15a, E15b and E15c, and has natural productivity. The AOF in E15a, E15b, and E15c is separately about: $6.6 \times 10^{4} \mathrm{~m}^{3} / \mathrm{d}, \quad 9.4 \times 10^{4} \mathrm{~m}^{3} / \mathrm{d}$, and $5.6 \times 10^{4} \mathrm{~m}^{3} / \mathrm{d}$.

By using Figure.3, the distribution of the R35, $K$ and $\Phi$ could be obtained, as shown in Table I. The physical property in this layer varies more in different place: The R35 Pore Throat Radius in Well 2 is about $1 \mu \mathrm{m}-4.3 \mu \mathrm{m}$, much larger than in Well 6 , that is the main reason for the phenomena that Well 2 has natural productivity but Well 6 has not.

TABLE I. R35, $\mathrm{K}$ and $\Phi$ values in E15a

\begin{tabular}{|c|c|c|c|c|c|}
\hline Well & $\begin{array}{c}\text { Range of } \\
\text { grain } \\
\text { diameter }\end{array}$ & Grad & $\begin{array}{l}\text { Degree of } \\
\text { roundness }\end{array}$ & $\begin{array}{l}\text { Contact } \\
\text { style }\end{array}$ & $\begin{array}{c}\text { Cemented } \\
\text { type }\end{array}$ \\
\hline $\begin{array}{c}\text { Well } \\
2\end{array}$ & $\begin{array}{c}0.15-0.40 \\
\mathrm{~mm}\end{array}$ & $\begin{array}{l}\text { mid - } \\
\text { high }\end{array}$ & $\begin{array}{l}\text { Subangular- } \\
\text { subrounded }\end{array}$ & $\begin{array}{l}\text { relief - } \\
\text { line }\end{array}$ & $\begin{array}{l}\text { press- } \\
\text { contact }\end{array}$ \\
\hline $\begin{array}{c}\text { Well } \\
4\end{array}$ & $\begin{array}{c}0.25-0.50 \\
\mathrm{~mm}\end{array}$ & high & subrounded & line & contact \\
\hline $\begin{array}{l}\text { Well } \\
6\end{array}$ & $\begin{array}{c}0.13-0.35 \\
\mathrm{~mm}\end{array}$ & $\begin{array}{l}\text { mid - } \\
\text { high }\end{array}$ & $\begin{array}{l}\text { Subangular- } \\
\text { subrounded }\end{array}$ & $\begin{array}{l}\text { point - } \\
\text { line }\end{array}$ & contact \\
\hline
\end{tabular}


- Detrital component and texture

The lithologic characters of E15 layer in Well 2, Well 4, and Well 6 are basically the same: lithic arkose, quartz content is about $62 \%-74 \%$, feldspar content is about $11 \%$ $19 \%$, lithic content is about $14 \%-20 \%$.

The quartz content in Well 2 is lower than in Well 4 and Well 6, as shown in Figure.4. The interstitial material content is about $6 \%-14.5 \%$, the cemented phenomenon hasn't been appeared.

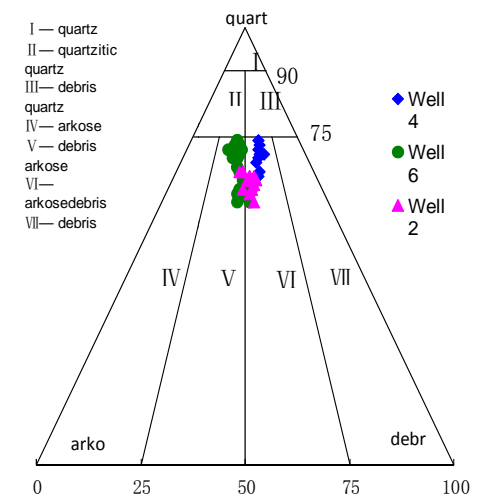

Figure 4. Classification of core component

The thin slice and size parameters are shown in Table II. The E15a is mainly belonged to fine sandstone, and sorted middle-high. Other parameters such as degree of roundness, contact style, and cemented type are also shown in this table.

TABLE II. Structure characteristics of the wells

\begin{tabular}{ccccc}
\hline Well & Layer & R35, $\mu \mathrm{m}$ & Permeability, mD & Porosity, \% \\
\hline Well 2 & E15a & $1-4.3$ & $0.2-8.5$ & $10-13.7$ \\
Well 4 & E15a & $0.12-1.3$ & $4-60$ & $11.5-14.6$ \\
Well 6 & E15a & $0.04-0.2$ & $0.03-0.2$ & $5-11.5$ \\
\hline
\end{tabular}

- Diagenesis type

Diagenesis has the main types: compaction, pressure solution, cementation, replacement, dissolution and recrystallization. For the LS gas field, the main types are: compaction, cementation and dissolution. This section researched and compared the characteristics of the diagenesis in Well 2, 4, and 6.

- Compaction

The contact style of E15 is point - line, line, relief - line, as shown inFigure.5a. It followed compression deformation by glimmer or plastic particles, as shown inFigure.5b. The reservoir has small pores and narrower pore throats. Compaction discharged water is the main source of pore water, and probably become the main agent of other epidiagenesis.

- Cementation

The cement is mainly calcite and dolomite (as shown in Figure.5c), and subordinately siliceous (as shown in Figure.5d), iron cementation local development, rare kaolinite cementation. The main type of carbonate cementation is intergranular cementation, and secondary porosity filler (as shown in Figure.5d).

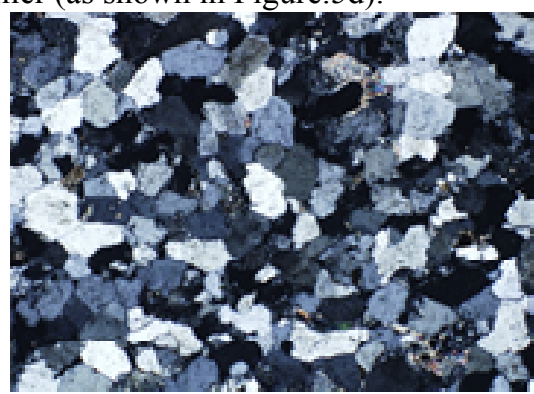

Fig.5 (a)

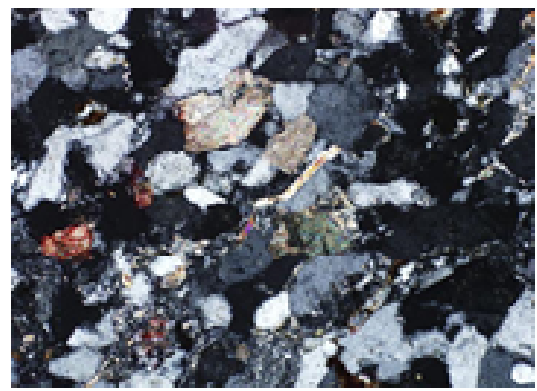

Fig.5 (b)

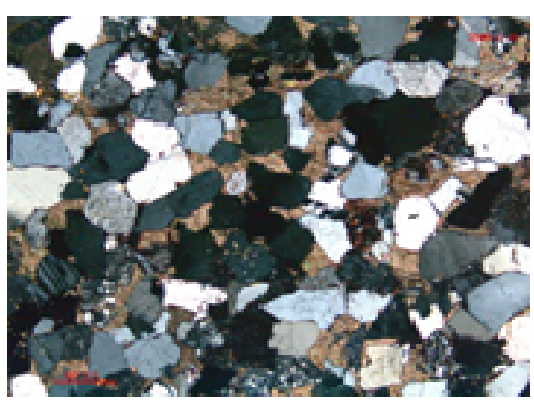

Fig.5 (c)

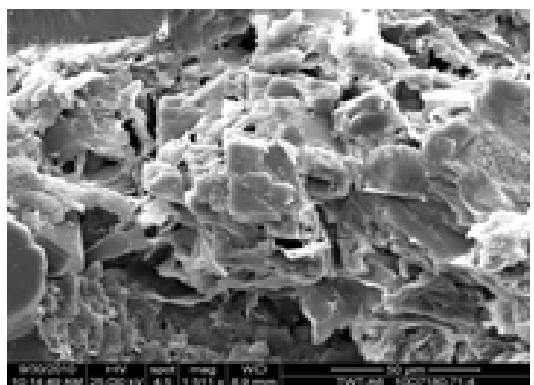

Fig.5 (d) 


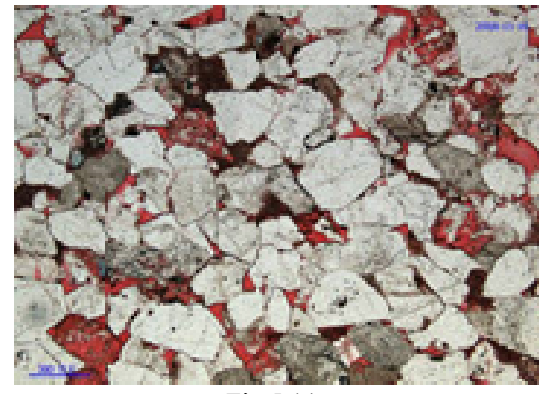

Fig.5 (e)

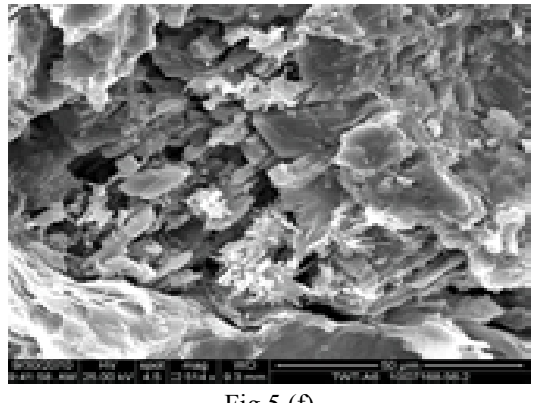

Fig.5 (f)

Figure 5. Characteristics of the diagenesis for the reservoir E15a

Use the chart (Houseknecht D Wof, 1987) to conduct the quantitative research for the compaction and cementation of E15, Well2, Well 4, and Well 6, the result shows that: the initial porosity of the core was declined by $27 \%-31 \%$ follow the effect of compaction and cementation (as shown in Figure.6).

\section{Cementation content, \%}

20

30

40

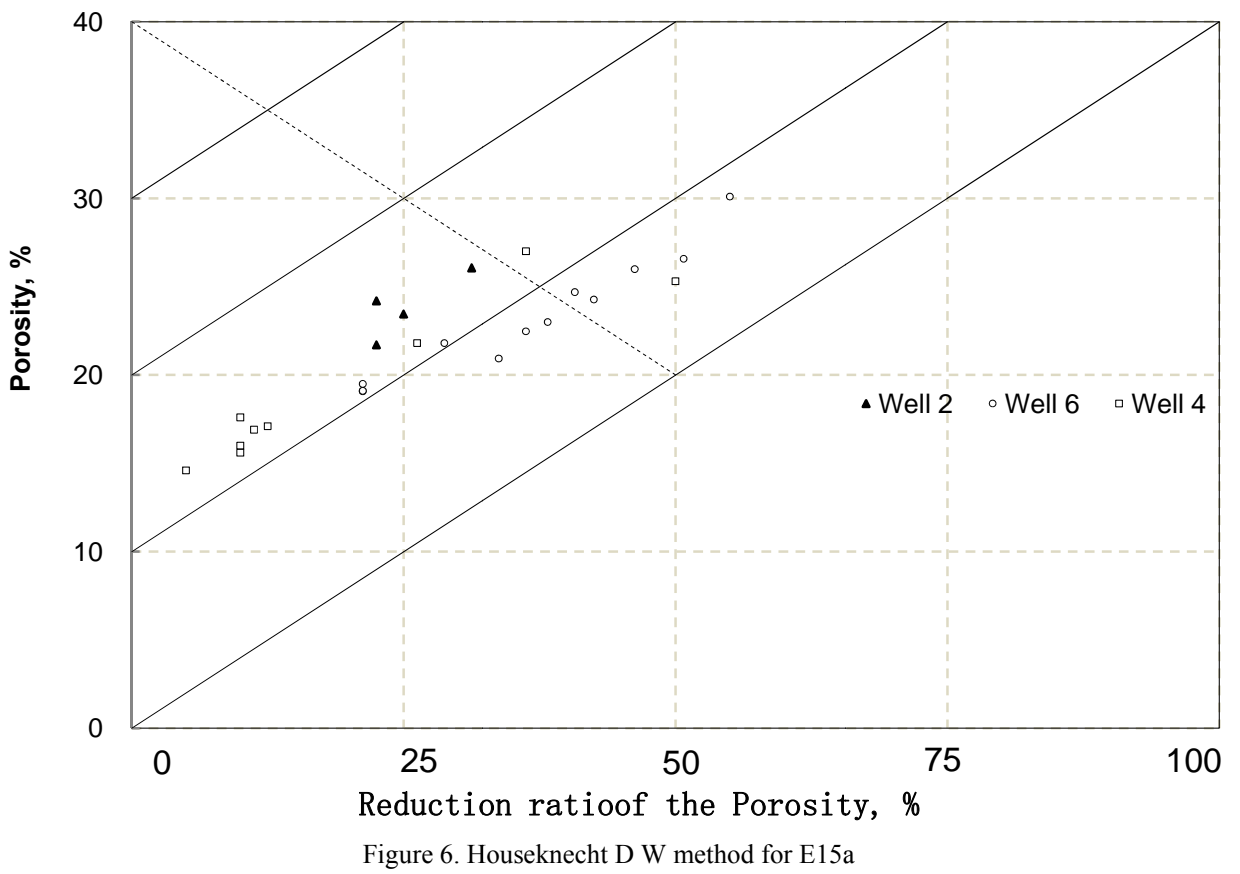

For Well 2, the main reason is compaction, and the subordinate reason is cementation. For Well 4, the main reason is compaction. For Well 6, the effect ratios of compaction and cementation are approximately equal.

- Dissolution

As the main constructive diagenesis, the dissolution could effectively improve the reservoir properties by generating secondary porosity. The common secondary porosity contains secondary intergranular pore feldspar, debris, soluble granules, tablets bore, etc.

The dissolutions in the three Wells are different. Well 2 and Well 4 were rarely filled with cements (as shown in
Figure.5e), as a result, the pores has been saved in varying degrees. For Well 6, the pores were filled again with the cements in later period (as shown in Figure.5f).

As a result, the R35 Pore Throat Radius in Well 6 is much small than in Well 2 and Well 4 (as shown in Table.1).

As can be seen in Figure.7, the throat radius in Well 6 is smaller than in Well 2 and Well 4, and this comparison could be searched in the chart (Figure. 3 and Table.1). As a result, the chart based on R35 Pore Throat Radius could effectively make characterization of the physical property in each reservoir. 


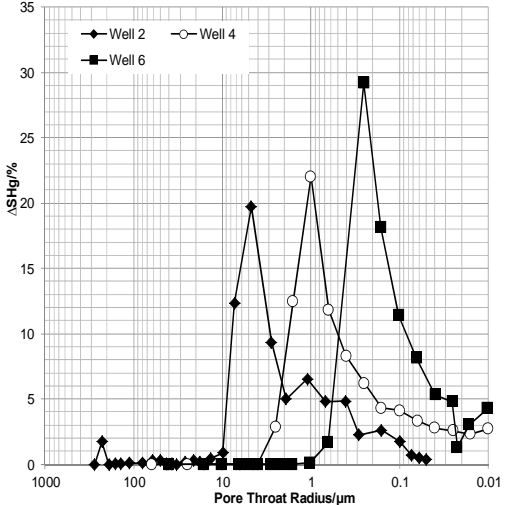

Figure 7. Pore characteristics of the 3 Wells

\section{CONCLUSIONS}

The following conclusions could be drawn according to the results obtained in this study:

New equations and parameters which are suitable for the LS gas field could be obtained in this study.

The reservoir classification and evaluation Chart of R35 could help to evaluate the reservoir physical properties intuitively and efficiently. And it could provide reference to the other evaluation work.

The effects of finely rock structure, low porosity, compaction and cementation on the reduction of the core original porosity are close to each other.

The preservation and dissolution cementation in the later period are the main factors leading to changes in reservoir properties.

\section{ACKNOWLEDGEMENTS}

The author Yangfan Li would like to acknowledge the colleagues for their hard work and contribution in this research. All the authors would like to acknowledge the leaders of CNOOC Ltd-Shanghai for the support and permission to publish this paper.

\section{REFERENCES}

[1] Z. Q. Wang, C. M. Zhang, G. W. Hou. Integrated Evaluation of Fan Delta Compacted and Low Permeable Sandstone Reservoir of Anpeng Deep Zone. Journal of Jianghan Petroleum Institute. Vol 24, No 3, Sep 2002.

2] H. F. Tang, S. M. Peng, Y. C. Zhao. Characteristics of Pore Structure and Reservoir Evaluation in $\mathrm{H} 2+3$ Tight Gas Reservoir, Daniudi Gas Field. Journal of Mineralogy and Petrology. Volume 26, Number 3, Total 105.

[3] Kolodzie S J. The Analysis of Pore Throat Size and Use of Waxman Smit to Determine OOIP in Spindle field. SPE9382 [C]. Presented at the 55th Annual Technical Conference. USA: Colorado, 1980: 10.

[4] Pittman E. D. Relationship of porosity and permeability to various parameters derived from mercury injection-capillary pressure curves for sandstone [J]. AAPG Bulletin, 1992, 76(2): 191-198.

[5] Aguilera R. Incorporating Capillary Pressure, Pore Aperture Radii, Height Above Free Water Table, and Winland R35 Values on Pickett Plots [J]. AAPG Bulletin,2002, 86 (4): 605-624.

[6] Aguilera R. Intergration of Geology, Petrophysics, and Reservoir Engineering for Characterization of Carbonate Reservoirs through Pickett Plots [J]. AAPG Bulletin, 2004, 88(4): 433-446.

[7] Housekencht D. W. Assessing the relative importance of compaction processes and cementation to reduction of porosity in sandstone $[\mathrm{J}]$. AAPG Bulletin, 1987, 71 (6): 633-542.

[8] C. M. Wang, C. R. Pei. Using minus-cement point diagram to evaluate Paleogene sandstone reservoir in Xihu Depression. Fault-Block Oil \& Gas Field. 1005-8907 (2010) 01-052-03. 